\title{
PEMODELAN BAYESIAN KONSUMSI RUMAH TANGGA AGREGAT MENGGUNAKAN PRIOR ZELLNER
}

\author{
Muhammad Fajar ${ }^{1 *}$ \\ ${ }^{1}$ Badan Pusat Statistik Provinsi Banten \\ mfajar@bps.go.id
}

\begin{abstract}
In the development of statistics, there are two views of parameters, namely frequentist and Bayesian. In Bayesian, the parameter is a random variable, not a constant like a frequentist view. The research aims to estimate the function or model of household consumption agrees using the Bayesian method. The data used in this study are GDP (y) and household consumption (x) at constant prices (2000) for the 1983Q1 - 2016Q4 period sourced from the Statistics-Indonesia. This study results that the Bayesian regression modeling of the household consumption function agrees with Zellner's previous use. The income coefficient in this model is significant and gets a marginal propensity to consume the value of 0.5702 . This implies that more than half of people's income is used for consumption purposes.
\end{abstract}

Keywords: bayesian, konsumsi, rumah tangga, prior, regresi.

\section{PENDAHULUAN}

Pengeluaran konsumsi rumah tangga adalah bagaimana keputusan rumah tangga menentukan berapa banyak atau berapa besar pendapatannya yang digunakan untuk konsumsi barang dan jasa dalam periode tertentu. Konsumsi agregat adalah seluruh jumlah pengeluaran konsumsi rumah tangga untuk barang dan jasa dalam suatu perekonomian. Beberapa hal yang menentukan konsumsi agregat antara lain adalah: (1) pendapatan rumah tangga, (2) kekayaan rumah tangga, (3) tingkat suku bunga, (4) harapan-harapan rumah tangga terhadap masa depan. Tetapi menurut penulis, pendapatan rumah tangga merupakan variabel yang berpengaruh besar pada konsumsi rumah tangga dibandingkan variabel lainnya karena konsumsi rumah tangga menyumbang share terbesar dibandingkan komponen lainnya dalam pendapatan nasional. Metode statistika yang berguna untuk menginvestigasi hubungan antara variabel respon (dependent) dengan satu atau lebih variabel prediktor yang dirumuskan kedalam persamaan matematis adalah regresi. Tujuan analisis regresi adalah untuk melakukan prediksi, pemilihan variabel, spesifikasi model dan estimasi parameter koefisien regresor (Myers, 2000).

Dalam statistika terdapat dua pandangan berbeda dalam memandang sebuah parameter, yaitu frequentist dan bayesian. Menurut pandangan frequentist bahwa parameter adalah sebuah nilai tetap (konstan), sedangkan dalam pandangan bayesian terdapatnya informasi terhadap parameter yang ditaksir yang disebut prior. Karena adanya informasi prior yang diterapkan dan menganggap parameter sebagai variabel random. Atas dasar tersebut, destimasi parameter regresi dapat dilakukan dengan pendekatan bayesian. Penulis dalam paper ini akan melakukan pemodelan regresi bayesian konsumsi agregat rumah tangga.

\section{TINJAUAN PUSTAKA}

\subsection{Konsumsi Rumah Tangga}

Konsumsi rumah tangga adalah pengeluaran atas barang dan jasa oleh rumah tangga untuk tujuan konsumsi. Dalam hal ini rumah tangga berfungsi sebagai pengguna akhir (final demand) dari berbagai jenis barang dan jasa yang tersedia dalam perekonomian. Rumah 
tangga didefinisikan sebagai individu atau kelompok individu yang tinggal bersama dalam suatu bangunan tempat tinggal. Pendapatan yang diterima rumah tangga digunakan untuk membeli makanan, membeli pakaian, membiayai jasa pengangkutan, dan lain-lain. Barangbarang tersebut dibeli oleh rumah tangga untuk memenuhi kebutuhannya dan perbelanjaan tersebut dinamakan konsumsi, yaitu membeli barang dan jasa untuk memuaskan keinginan memiliki dan menggunakan barang tersebut.

Fungsi konsumsi sebagai sebuah skedul konsumsi yang direncanakan pada berbagai tingkat pendapatan disposabel. Keynes percaya bahwa skedul konsumsi yang direncanakan ini merupakan "hukum psikologis yang fundamental", dimana perubahan konsumsi lebih kecil dari perubahan pendapatan disposabel. Sehingga, marginal propensity to consume (MPC) bernilai lebih kecil dari satu untuk fungsi konsumsi rumah tangga:

$$
y=\gamma_{0}+\gamma_{1} x_{d}+\epsilon
$$

dengan $y$ : konsumsi rumah tangga, $x_{d}$ : pendapatan disposabel rumah rangga, $\epsilon$ : random eror. Karena variabel pendapatan disposabel rumah tangga sangat sulit diukur dan belum tersedia, maka penulis menggunakan proxy produk domestik bruto, sehingga persamaan (1) menjadi:

$$
y=\alpha_{1}+\beta_{1} x+\varepsilon
$$

dengan $x$ : produk domestik bruto (PDB), $\beta_{1}$ : nilai marginal propensity to consume (MPC), $\varepsilon$ : random eror.

Sementara itu, penelitian mengenai pemodelan konsumsi rumah tangga, antara lain Song, et al (1996) mengestimasi fungsi konsumsi agregat menggunakan model time varying parameter (TVP), hasilnya menunjukkan bahwa TVP fungsi konsumsi agregat merupakan representasi yang baik untuk melihat perubahan perilaku konsumen di Cina sepanjang waktu. Szekely (1993) menunjukkan bahwa variabel pendapatan dan konsumsi yang digunakan untuk pemodelan ECM (Error Correction Mechanism) menggunakan first difference menyebabkan misspesified karena kedua variabel tersebut terintegrasi pada order (2), tingkat bunga berpengaruh jangka panjang dan pendek pada hubungan pendapatan dan konsumsi. Hu dan Mc Aleer (2003) menunjukkan adanya kointegrasi antara konsumsi dan PDB, dan perubahan struktural dalam hubungan jangka pendek antara konsumsi dan PDB menyiratkan bahwa reformasi ekonomi memiliki dampak signifikan atas konsumsi dalam jangka pendek.

\subsection{Analisis Bayesian}

Analisis bayesian memanfaatkan dua sumber informasi dalam mengestimasi parameter suatu model statistik. Sumber informasi pertama berasal dari data sampel dan sumber informasi kedua berasal dari opini ahli, yang biasa disebut informasi prior. Informasi yang berasal dari data sampel digali dari suatu fungsi likelihood sedangkan informasi prior dapat berasal dari opini subjektif ahli atau berasal dari penelitian terdahulu. Berbagai ahli dapat memberikan informasi prior yang berbeda. Ketidakpastian (uncertainty) opini ahli ini diekspresikan melalui suatu distribusi peluang yang disebut distribusi prior. Gabungan dari kedua sumber informasi tersebut membentuk suatu informasi posterior (distribusi posterior).

Teorema Bayes digunakan untuk menggabungkan kedua sumber informasi diatas. Misalkan parameter yang menjadi perhatian adalah vektor $\boldsymbol{\theta}$ dan data sampelnya adalah vektor $\boldsymbol{z}$. Parameter $\boldsymbol{\theta}$ dan sampel $\boldsymbol{z}$ keduanya adalah variabel acak dengan fungsi densitas gabungan $h(\boldsymbol{\theta}, \boldsymbol{z})$. Informasi sampel berasal dari fungsi likelihood $f(\mathbf{z} \mid \boldsymbol{\theta})$ dan informasi prior yang diberikan adalah $g(\boldsymbol{\theta})$, maka fungsi gabungan $h(\boldsymbol{\theta}, \boldsymbol{z})$ dapat dinyatakan:

sehingga:

$$
h(\boldsymbol{\theta}, \mathbf{z})=g(\boldsymbol{\theta} \mid \mathbf{z}) f(\mathbf{z})=f(\mathbf{z} \mid \boldsymbol{\theta}) g(\boldsymbol{\theta})
$$




$$
g(\boldsymbol{\theta} \mid \mathbf{z})=\frac{f(\mathbf{z} \mid \boldsymbol{\theta}) g(\boldsymbol{\theta})}{f(\mathbf{z})}
$$

karena $f(\mathbf{z})$ merupakan konstan, maka persamaan (3) dapat dinyatakan:

$$
g(\boldsymbol{\theta} \mid \mathbf{z}) \propto f(\boldsymbol{z} \mid \boldsymbol{\theta}) g(\boldsymbol{\theta})
$$

dengan $g(\boldsymbol{\theta} \mid \mathbf{z})$ adalah fungsi densitas posterior. Secara filosofi persamaan (4) dapat dinyatakan:

informasi posterior $\propto$ informasi likelihood (sampel) $\mathrm{x}$ informasi prior

Teorema Bayes berbicara tentang informasi $\boldsymbol{\theta}$ sebelum dan sesudah sampel z terobservasi. Sebelum sampel z terobservasi, satu-satunya informasi tentang $\boldsymbol{\theta}$ diperoleh dari $g(\boldsymbol{\theta})$. Tetapi ketika sampel z telah diperoleh, informasi tentang $\boldsymbol{\theta}$ akan direvisi menjadi $g(\boldsymbol{\theta} \mid \mathbf{z})$. Dengan kata lain teorema Bayes merupakan sebuah metode yang optimal tentang bagaimana memperbaharui kepercayaan seseorang tentang parameter populasi setelah diberikannya informasi baru (Hoff, 2009). Dalam analisis bayes penentuan distribusi prior memegang peranan penting karena distribusi prior ini akan menentukan distribusi posterior yang akan digunakan sebagai alat inferensia. Box dan Tio (1973) menyatakan bahwa distribusi prior dapat diperoleh dari informasi sebelumnya mengenai parameter yang diestimasi. Distribusi prior menyatakan pengetahuan awal peneliti tentang parameter $\boldsymbol{\theta}$ sebelum melakukan observasi atau analisis terhadap data.

Prior ini bisa berdasarkan pada hasil penelitian sebelumnya, ataupun berdasarkan teoriteori yang ada. Bisa juga terjadi peneliti tidak memiliki informasi prior, hal ini juga dapat digambarkan dalam distribusi prior. Distribusi prior merupakan salah satu kunci dari inferensia bayesian dan menampilkan informasi tentang ketidakpastian parameter $\boldsymbol{\theta}$. Penentuan distribusi prior dapat dilakukan dengan mempertimbangkan berbagai informasi yang akan digunakan sebagai distribusi prior dan sifat dari distribusi posterior yang akan dihasilkan. Berbagai distribusi prior telah dikembangkan dalam banyak literatur, namun secara garis besar dapat dikelompokkan berdasarkan tiga jenis prior, yaitu conjugate prior, non-informative prior dan subjective prior.

Suatu prior dikatakan conjugate prior jika distribusi posterior yang dihasilkan berasal dari family fungsi densitas peluang (pdf) yang sama dengan prior (Hogg, et al, 2005). Noninformative prior adalah prior yang digunakan ketika pengetahuan awal tentang parameter model tidak ada atau sangat sedikit dan tidak pasti. Salah satu pendekatan prior ini adalah dengan memilih prior yang secara aproksimasi berdistribusi uniform dalam domain ruang parameter yang diteliti. Secara umum noninformative prior diperoleh dari data sampel dan model yang sedang diteliti dalam penyusunan distribusi prior tersebut. Sementara subjective prior adalah prior berdasarkan pada pengalaman sebelumnya dan berdasarkan pemikiran peneliti tentang kemungkinan nilai parameter yang diteliti (Muller, 2012). Selain distribusi prior, komponen lain yang membentuk distribusi posterior adalah fungsi likelihood. Fungsi likelihood merupakan fungsi distribusi bersama dari variabel respon yang dihasilkan dari data.

\subsection{Regresi Linier}

Secara umum persamaan (2) dapat dinyatakan dalam notasi matriks sebagai berikut: dengan:

$$
\boldsymbol{y}=\alpha \mathbf{1}_{n}+\boldsymbol{X} \boldsymbol{\beta}+\boldsymbol{\varepsilon}
$$

$\boldsymbol{y}$ : variabel respon $\left(y_{1}, \ldots, y_{n}\right), \alpha$ : konstan, $\boldsymbol{\beta}$ : vektor koefisien regresi berukuran $\mathrm{p} \times 1$. $\boldsymbol{X}=\left[\begin{array}{lll}\boldsymbol{x}_{1} \ldots & \boldsymbol{x}_{p}\end{array}\right]$, matriks desain berukuran $n \times \mathrm{x} p$, sebanyak $p$ variabel prediktor.

$\boldsymbol{\varepsilon}$ : vektor random eror berdistribusi i.i.d $N\left(\mathbf{0}_{n}, \sigma^{2} \boldsymbol{I}_{n}\right)$. 
Persamaan (5) diestimasi dengan metode ordinary least square atau maximum likelihood diperoleh estimator untuk koefisien regresi adalah:

\section{METODE PENELITIAN}

$$
\widehat{\boldsymbol{\beta}}=\left(\boldsymbol{X}^{T} \boldsymbol{X}\right)^{-1} \boldsymbol{X}^{T} \boldsymbol{y}
$$

\subsection{Sumber Data}

Data yang digunakan dalam penelitian ini adalah PDB dan konsumsi rumah tangga atas dasar harga konstan (2000) periode 1983Q1 - 2016Q4 yang bersumber dari Badan Pusat Statistik.

\subsection{Regresi Bayesian}

Zellner $(1971,1984)$ mengusulkan prior Gaussian untuk $\boldsymbol{\beta}$ pada regresi:

$$
\boldsymbol{\beta} \mid \alpha, \sigma^{2} \sim N_{p}\left(\widetilde{\boldsymbol{\beta}}, g \sigma^{2}\left(\boldsymbol{X}^{T} \boldsymbol{X}\right)^{-1}\right)
$$

dan prior noninformatif untuk $\alpha, \sigma^{2}$ :

$$
\pi\left(\alpha, \sigma^{2}\right) \propto \sigma^{-2}
$$

dengan asumsi bahwa matriks $\mathrm{X}$ full rank, dan $g$ dapat diinterpretasikan konstan proporsional terbalik terhadap informasi yang tersedia. Marin dan Robert (2013) memberikan nilai g sama dengan banyaknya jumlah sampel $(g=n)$ yang memberikan arti bahwa prior memberikan bobot yang sama sebagai satu observasi dari sampel. Marin dan Robert (2013) bahwa prior $\pi\left(\alpha, \beta, \sigma^{2}\right)$ dapat didekomposisi menjadi:

$$
\pi\left(\alpha, \boldsymbol{\beta}, \sigma^{2}\right) \propto\left(\sigma^{2}\right)^{-\frac{p}{2}} \exp \left[-\frac{1}{2 g \sigma^{2}}\left\{\boldsymbol{\beta}^{T} \boldsymbol{X}^{T} \boldsymbol{X} \boldsymbol{\beta}^{T} \boldsymbol{X}^{T} \boldsymbol{P} \boldsymbol{X} \widetilde{\boldsymbol{\beta}}\right\}\right] \times \sigma^{-2} \exp \left[-\frac{1}{2 g \sigma^{2}} \widetilde{\boldsymbol{\beta}}^{T} \boldsymbol{X}^{T} \boldsymbol{P} \boldsymbol{X} \widetilde{\boldsymbol{\beta}}\right]
$$

dengan $\boldsymbol{P}=\boldsymbol{X}\left(\boldsymbol{X}^{T} \boldsymbol{X}\right)^{-1} \boldsymbol{X}^{T}$, maka:

$$
\begin{aligned}
\pi\left(\alpha, \boldsymbol{\beta}, \sigma^{2} \mid \boldsymbol{y}\right) \propto & \left(\sigma^{2}\right)^{-\frac{n}{2}-\frac{p}{2}-1} \exp \left[-\frac{1}{2 \sigma^{2}}\left(\boldsymbol{y}-\overline{\boldsymbol{y}} \mathbf{1}_{n}-\boldsymbol{X} \boldsymbol{\beta}\right)^{T}\left(\boldsymbol{y}-\overline{\boldsymbol{y}} \mathbf{1}_{n}-\boldsymbol{X} \boldsymbol{\beta}\right)\right] \times \\
& \exp \left[-\frac{n}{2 \sigma^{2}}(\overline{\boldsymbol{y}}-\alpha] \times \exp \left[-\frac{1}{2 g \sigma^{2}} \widetilde{\boldsymbol{\beta}}^{T} \boldsymbol{X}^{T} \boldsymbol{P} \boldsymbol{X} \widetilde{\boldsymbol{\beta}}\right] \times\right. \\
& \exp \left[-\frac{1}{2 g \sigma^{2}}\left\{\boldsymbol{\beta}^{T} \boldsymbol{X}^{T} \boldsymbol{X} \boldsymbol{\beta}-2 \boldsymbol{\beta}^{T} \boldsymbol{X}^{T} \boldsymbol{P} \boldsymbol{X} \widetilde{\boldsymbol{\beta}}\right\}\right]
\end{aligned}
$$

karena $\mathbf{1}_{n}{ }^{T} \boldsymbol{X}=\mathbf{0}$, (bahwa variabel prediktor di-centered), maka:

$$
\begin{aligned}
\pi\left(\alpha, \boldsymbol{\beta}, \sigma^{2} \mid \boldsymbol{y}\right) \propto & \left(\sigma^{2}\right)^{-\frac{n}{2}-\frac{p}{2}-1} \exp \left[-\frac{1}{2 \sigma^{2}}\left(\boldsymbol{y}-\overline{\boldsymbol{y}} \mathbf{1}_{n}-\boldsymbol{X} \boldsymbol{\beta}\right)^{T}\left(\boldsymbol{y}-\overline{\boldsymbol{y}} \mathbf{1}_{n}-\boldsymbol{X} \boldsymbol{\beta}\right)\right] \times \\
& \exp \left[-\frac{n}{2 \sigma^{2}}(\overline{\boldsymbol{y}}-\alpha] \times \exp \left[-\frac{1}{2 g \sigma^{2}} \widetilde{\boldsymbol{\beta}}^{T} \boldsymbol{X}^{T} \boldsymbol{P} \boldsymbol{X} \widetilde{\boldsymbol{\beta}}\right] \times\right. \\
& \exp \left[-\frac{1}{2 g \sigma^{2}}\left\{\boldsymbol{\beta}^{T} \boldsymbol{X}^{T} \boldsymbol{X} \boldsymbol{\beta}-\mathbf{2} \boldsymbol{\beta}^{T} \boldsymbol{X}^{T} \boldsymbol{P} \boldsymbol{X} \widetilde{\boldsymbol{\beta}}\right\}\right]
\end{aligned}
$$

Implikasi bahwa $\boldsymbol{P} \boldsymbol{X}=\boldsymbol{P}$, maka persamaan (6) dapat dilihat bersyarat atas $\boldsymbol{y}, \boldsymbol{X}$ dan $\sigma^{2}$, sehingga parameter $\alpha$ dan $\boldsymbol{\beta}$ independen. Marin dan Robert (2013) menunjukkan distribusi posterior dari $\alpha$ dan $\boldsymbol{\beta}$ sebagai berikut:

$$
\begin{gathered}
\alpha \mid \sigma^{2}, \boldsymbol{y} \sim N_{1}\left(\overline{\boldsymbol{y}}, \frac{\sigma^{2}}{n}\right) \\
\beta \mid \boldsymbol{y}, \sigma^{2} \sim N_{p}\left(\frac{g}{g+1}\left(\widehat{\boldsymbol{\beta}}+\frac{\boldsymbol{X} \widetilde{\boldsymbol{\beta}}}{g}\right), \frac{\sigma^{2} g}{g+1}\left(\boldsymbol{X}^{T} \boldsymbol{X}\right)^{-1}\right)
\end{gathered}
$$




$$
\sigma^{2} \mid \boldsymbol{y} \sim I G\left[\frac{(n-1)}{2}, s^{2}+\frac{(\widetilde{\boldsymbol{\beta}}-\widehat{\boldsymbol{\beta}})^{T} \boldsymbol{X}^{T} \boldsymbol{X}(\widetilde{\boldsymbol{\beta}}-\widehat{\boldsymbol{\beta}})}{g+1}\right]
$$

dengan $\widehat{\boldsymbol{\beta}}=\left(\boldsymbol{X}^{T} \boldsymbol{X}\right)^{-1} \boldsymbol{X}^{T} \boldsymbol{y}$, distribusi posterior independen antara $\alpha$ dan $\boldsymbol{\beta}$ disebabkan kenyataan bahwa matriks $\mathrm{X}$ dipusatkan (centered). $I G(a, b)$ adalah distribusi invers Gamma dengan mean $b /(a-1)$ dan varians $b^{2} /\left((a-1)^{2}(a-2)\right) . s^{2}=\left(\boldsymbol{y}-\overline{\boldsymbol{y}} \mathbf{1}_{n}-\boldsymbol{X} \widehat{\boldsymbol{\beta}}\right)^{T}(\boldsymbol{y}-$ $\left.\overline{\boldsymbol{y}} \mathbf{1}_{n}-\boldsymbol{X} \widehat{\boldsymbol{\beta}}\right)$. Kemudian, Marin dan Robert (2013) juga menunjukkan ekspektasi dan varians dari distribusi posterior marginal sebagai berikut:

$\alpha$

Mean Posterior:

Variance Posterior:

$$
E^{\pi}(\alpha \mid \boldsymbol{y})=\overline{\boldsymbol{y}}
$$

$V^{\pi}(\alpha \mid y)=\kappa / n(n-3)$

dengan $\kappa=s^{2}+(\widetilde{\boldsymbol{\beta}}-\widehat{\boldsymbol{\beta}})^{T} \boldsymbol{X}^{T} \boldsymbol{X}(\widetilde{\boldsymbol{\beta}}-\widehat{\boldsymbol{\beta}}) /(g+1)$

\section{$\beta$}

Mean Posterior:

Variance Posterior:

$$
E^{\pi}(\boldsymbol{\beta} \mid \boldsymbol{y})=\frac{g}{g+1}\left(\widehat{\boldsymbol{\beta}}+\frac{\boldsymbol{X} \widetilde{\boldsymbol{\beta}}}{g}\right)
$$

$$
V^{\pi}(\boldsymbol{\beta} \mid \boldsymbol{y})=\frac{\kappa g}{\left(g+\underset{\sigma^{2}}{1)(n-3)}\right.}\left(\boldsymbol{X}^{T} \boldsymbol{X}\right)^{-1}
$$

Mean Posterior:

Variance Posterior:

$$
E^{\pi}\left(\sigma^{2} \mid \boldsymbol{y}\right)=\frac{\kappa}{(n-3)}
$$

$$
V^{\pi}\left(\sigma^{2} \mid \boldsymbol{y}\right)=\frac{\left(\frac{(\widetilde{\boldsymbol{\beta}}-\widehat{\boldsymbol{\beta}})^{T} \boldsymbol{X}^{T} \boldsymbol{X}(\widetilde{\boldsymbol{\beta}}-\widehat{\boldsymbol{\beta}})}{g+1}\right)^{2}}{\left(\frac{(n-1)}{2}-1\right)^{2}\left(\frac{(n-1)}{2}-2\right)}
$$

Dalam penelitian memberikan nilai $g=136$ (sebanyak jumlah observasi) dan $\widetilde{\boldsymbol{\beta}}=$ $\mathbf{0}_{p}$. Karena variabel prediktor di-centered mengakibatkan intersep pada regresi bayesian adalah rata-rata dari variabel respon. Penulis dalam penelitian menggunakan transformasi $\mathbf{1}_{n}{ }^{T} \boldsymbol{X}=\mathbf{0}$ dan $\mathbf{1}_{n}{ }^{T} \boldsymbol{y}=\mathbf{0}$, karena transformasi tersebut cocok dengan spesifikasi flat prior (Berger et al, 1998) dan juga penelitian ini memfokuskan pada koefisien regresi, sehingga persamaan (2) menjadi:

$$
y^{*}=\beta_{1} x^{*}+v
$$

dengan: $y^{*}=y-\bar{y}, x^{*}=x-\bar{x}$, interpretasi $\beta_{1}$ : MPC (tidak berubah walau variabel telah ditransformasi), $v$ : random eror.

\section{HASIL DAN PEMBAHASAN}

Secara visual, pola hubungan antara PDB riil dan konsumsi rumah tangga riil disajikan pada gambar 1 , terlihat hubungan diantara kedua variabel tersebut adalah linier. Jadi spesifikasi model pada persamaan (2) sudah tepat. 


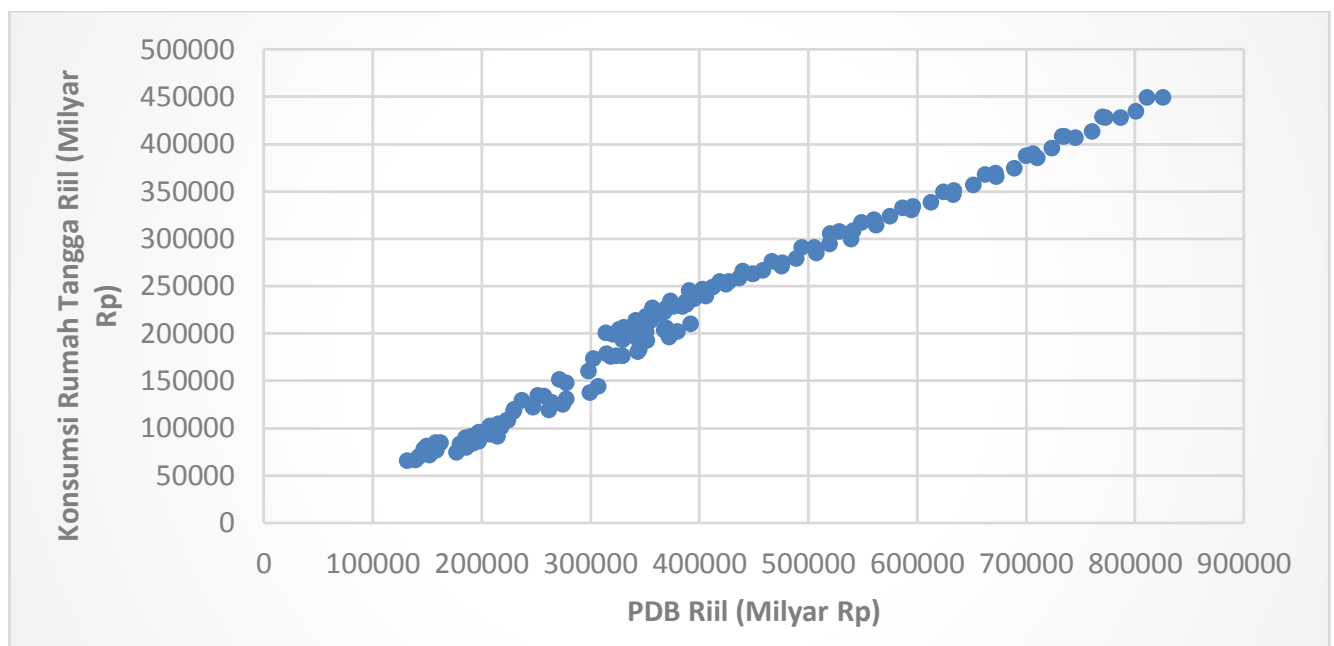

Gambar 1. Scatter Plot Antara PDB Riil $(x)$ dan Konsumsi Rumah Tangga Riil $(y)$ di Indonesia

Persamaan (10) diestimasi dengan menggunakan metode ordinary least square diperoleh estimator sebagai berikut:

$$
\begin{array}{rr}
\hat{y}^{*}= & 0.5744 x^{*} \\
\text { Standard Error } \quad(0.0066)
\end{array}
$$

Koefisien pada persamaan (11) adalah estimasi MPC untuk seluruh rumah tangga di Indonesia. Hasil penghitungan diperoleh MPC sebesar 0.5744, artinya jika terjadi kenaikan PDB sebesar 1 satuan, maka terjadi kenaikan untuk konsumsi sebesar 0.5744 satuan. MPC tersebut dapat diartikan juga bahwa jika secara agregat, rumah tangga mendapat tambahan pendapatan sebesar 1 milyar rupiah, maka 0.5744 milyar rupiah digunakan untuk konsumsi, sedangkan sisanya 0.4256 milyar rupiah tidak digunakan untuk konsumsi tetapi ditabung, sehingga nilai MPC berkisar antara 0 dan 1. Nilai MPC tersebut signifikan ditunjukkan dengan standard error yang kecil dan t-stat yang besar mencapai 86.9407.

Kemudian persamaan (10) diestimasi dengan metode bayesian, berikut hasil estimasinya:

$$
\text { Posterior Standard Deviation } \quad \hat{y}^{*}=0.5702 x^{*}
$$

Credible interval untuk koefisien regresi pada persamaan (12): $0.5547 \leq \hat{\beta}_{\text {bayes }} \leq 0.5857$, karena credible interval tersebut tidak mengandung nol, maka dapat disimpulkan bahwa koefisien regresi hasil estimasi bayes adalah signifikan. Hasil estimasi bayesian untuk koefisien regresi persamaan (12) adalah 0.5702, merupakan mean dari distribusi posterior $\beta$. Hasil estimasi MPC tersebut yang berbeda tipis dengan estimasi ordinary least square karena adanya informasi prior pada $\beta$. Nilai MPC sebesar 0.5702 , berarti jika terjadi kenaikan PDB sebesar 1 satuan, maka terjadi kenaikan untuk konsumsi sebesar 0.5702 satuan.

\section{KESIMPULAN}

Berdasarkan pembahasan sebelumnya dapat ditarik kesimpulan bahwa pemodelan regresi bayesian untuk fungsikonsumsi rumah tangga agregat dengan menggunakan prior Zellner dapat diaplikasikan. Adapun hasil pemodelan adalah sebagai beikut: 


$$
\hat{y}^{*}=0.5702 x^{*}
$$

Dari fungsi konsumsi rumah tangga agregat tersebut dapat diketahui nilai MPC untuk di Indonesia sebesar 0.5702. Jika terjadi kenaikan PDB sebesar 1 satuan, maka terjadi kenaikan untuk konsumsi sebesar 0.5702 satuan. Jadi, pendapatan masyarakat lebih dari setengahnya digunakan untuk keperluan konsumsi.

Untuk penelitian selanjutnya, dapat dimasukkan unsur variabel lainnya selain pendapatan dan sangat penting juga untuk mengakomodir shock seperti krisis ekonomi. Sehingga, dari model regresi dapat dilihat stabilitas parameter dalam model dengan tetap berpegang dalam kerangka analisis bayesian.

\section{DAFTAR PUSTAKA}

Berger, J., Pericchi, L. dan Varshavsky, J. 1998. Bayes factors and marginal distributions in invariant situations. Sankhya: The Indian Journal of Statistics, Series A, 60, 307-321.

Box, G.E.P. and Tiao, G.C. 1992. Bayesian Inference in Statistical Analysis. USA. John Wiley and Sons, Inc.

Hoff, P.D. 2009. A First Course in Bayesian Statistical Methods. New York. Springer.

Hogg, R.V., McKean, J.W., and Craig, A.T. 2005. Introduction to Mathematical Statistics. Sixth Edition. USA. Pearson Prentice Hall.

$\mathrm{Hu}, \mathrm{B}$. and McAleer, M. 2003. Time series analysis of aggregate consumption in China. MODSIM 2003: International Congress on Modelling and Simulation 3, 1412-1426.

Marin, J.M. and Robert, C. 2013. Essential Bayesian with R. Second Edition. New York. Springer.

Muller, C.J.B. 2012. Bayesian Approaches of Markov Models Embedded in Unbalanced Panel Data. Dissertation. Stellenbosch University.

Myers, R.H. 2000. Classical and Modern Regression with Application. Second Edition. Boston. Duxbury Press.

Song, H., Liu, X. and Romilly, P. (1996). A time varying parameter approach to the Chinese aggregate consumption function. Economics of Planning 29,185-203

Szekely, I.P. 1993l. What went wrong with the Hungarian consumption function? An econometric investigation of the time series aggregate consumption function for Hungary for 1960 - 1989. Economics of Planning 26, 39-54.

Zellner, A. (1971). An Introduction to Bayesian Econometrics. New York. John Wiley.

Zellner, A. (1984). Basic Issues in Econometrics. Chicago. University of Chicago Press. 